\title{
An Experimental Study on Cracking Behavior of Precracked Sandstone Specimens under Seepage Pressure
}

\author{
Qibin Lin $\mathbb{D}^{1},{ }^{1}$ Ping Cao, ${ }^{1}$ Hua Wang, ${ }^{1}$ and Rihong Cao ${ }^{1,2}$ \\ ${ }^{1}$ School of Resources and Safety Engineering, Central South University, Changsha, Hunan 410083, China \\ ${ }^{2}$ School of Civil, Environmental and Mining Engineering, The University of Western Australia, Perth, WA 6009, Australia \\ Correspondence should be addressed to Qibin Lin; qblin@csu.edu.cn
}

Received 13 November 2017; Accepted 17 January 2018; Published 11 March 2018

Academic Editor: Constantin Chalioris

Copyright (c) 2018 Qibin Lin et al. This is an open access article distributed under the Creative Commons Attribution License, which permits unrestricted use, distribution, and reproduction in any medium, provided the original work is properly cited.

This paper aims to investigate the strength and failure mechanism of fractured rock under seepage pressure. For this purpose, precracked sandstone specimens were prepared with different fissure angles, and a seepage pressure loading device was created. Together with the acoustic emission (AE) system, the loading device was adopted to perform uniaxial compression tests with or without seepage pressure. The main results are as follows. Combined with axial stress-strain curves, photographic monitoring results and the output of $\mathrm{AE}$ counts and rock failure process can be generally divided into four stages: microcrack closure, elastic deformation, crack growth and propagation, and final failure. The seepage pressure had a significant effect on the mechanical properties of the specimens: the specimens under seepage pressure lagged far behind those without seepage pressure in peak strength but maintained a comfortable lead in peak strain. Under seepage pressure, the typical failure features of the specimens varied with the fissure angles: the specimens with small fissure angles (i.e., $\left[0^{\circ}, 30^{\circ}\right]$ ) mainly underwent tensile failure; those with medium fissure angles (i.e., $\left.\left[30^{\circ}, 60^{\circ}\right]\right)$ suffered from shear failure; and those with large fissure angles (i.e., $\left[60^{\circ}, 75^{\circ}\right]$ ) were prone to tensile-shear failure.

\section{Introduction}

As a complex natural medium, the rock mass acquires various defects under tectonic actions, including microcracks, pores, and joints. These defects directly bear on the physical and mechanical properties of the rock mass. Much research has been done on the crack propagation mechanism of precracked rock under uniaxial compression. The previous studies have shown that two kinds of cracks, e.g., wing cracks and secondary cracks, may initiate from the tip of a single open crack under uniaxial compression [1-4]. Wing cracks are induced by the tensile force, while secondary cracks are the result of shear force. In the loading process, wing cracks appear earlier than secondary cracks. The secondary cracks make the failure of the whole specimen. The mechanical properties and failure modes of materials with two, three, or more cracks have also been explored in details. For instance, Shen [5] tested a number of parallel crack specimens made of gypsum specimens under uniaxial compression and pointed out three failure modes at different fissure angles: tensile failure, shear failure, and mixed failure. Based on the crack propagation in different sample materials, Wong and Einstein $[6,7]$ carried out uniaxial compressive tests on the failure of marble and gypsum specimens and presented seven modes of cracks which initiate and propagate from crack tips. Bobet and Einstein [8] conducted uniaxial compressive tests on gypsum specimens with parallel cracks and compared the initiation, propagation, and coalescence of wing cracks and secondary cracks with open or closed fissure. On this basis, the scholar put forward eight different crack coalescence modes and disclosed the strength impact of these modes. With the continuous improvement of test devices and methods, high-precision instruments have been employed to capture the crack coalescence process. For example, high-speed video cameras were used to study the failure process of precracked specimens and obtained the footage on the whole process from crack initiation and crack propagation to final failure 
[6, 7, 9-13]. Meanwhile, many numerical methods have been introduced to simulate the crack initiation and propagation, namely, the finite-element method (FEM), the boundaryelement method (BEM), and the discrete-element method (DEM). Recent years saw the extensive application of particle flow code (PFC) in the simulation of crack propagation. PFC, that is, a kind of DEM, has been applied to simulate crack initiation and propagation process of brittle materials under uniaxial compressive loading. The simulated results often agree well with test results. Bahaaddini et al. [14] established multicrack specimens by PFC3D and investigated how the compressive strength, deformation modulus, and failure modes of rock mass change with joint geometrical parameters. The fissure angle refers to the angle between the crack and the loading direction. Wong et al. [15] performed a uniaxial compressive test on brittle specimens with a single hole. And material failure process analysis code (MFPA2D), a numerical approach based on microdamage mechanics, is employed to explain the failure modes and strength features of the specimens. The particle flow code in two dimensions (PFC2D) program is adopted, and the parallel bond model is introduced to study the crack coalescence modes and the specimen failure process [16].

Focusing on the effect of rock defects on mechanical properties, the above studies fail to tackle the mechanical mechanism of flawed rocks under seepage pressure. In fact, the rock mass is severely affected by water in actual projects, such as reservoirs, underground caverns, side slopes, and tunnels. The water exerts both chemical and physical effects on the rock mass. The chemical effect weakens the rock strength, reshapes the joint surface, and lowers the internal friction angle and bond coefficient. The physical effect of water is mainly attributed to groundwater. The groundwater alters the stress state of the flawed rock mass and reduces the effective stress on the structural surface, leading to the crack propagation and coalescence. The crack development, in return, makes the groundwater effect increasingly dynamic. In the long run, the physical effect will cause catastrophic mining accidents. For safety underground mining and disaster prevention, it is meaningful to explore crack initiation, propagation, and coalescence under seepage pressure.

To reveal the failure mechanisms of flawed rocks under seepage pressure, Zhao et al. [17] dug deep into the damage mechanisms of cracks under seepage pressure and established a damage mechanics model of cracked rocks and the evolution equation of crack tip stress intensity factor under both compression-shear stress field and the seepage field. Based on the fracture mechanics, Zhou et al. [18] theoretically analyzed the crack tip crack initiation law and the stress intensity factors under seepage pressure. Li et al. [19] adopted a numerical program, Realistic Failure Process Analysis 2-D (RFPA2D) to simulate the crack initiation, propagation, and coalescence of reinforced specimens under true triaxial compression and hydraulic pressure and studied the effects of the confining stress ratio, gravel sizes, and gravel volume content on the mechanical properties of the specimens.

So far, there are few experimental studies on flawed rock materials under seepage pressure, despite the numerous theoretical studies and numerical simulations on fracture and failure of flawed rocks under seepage pressure. Therefore, uniaxial compression experiments were carried on sandstone specimens containing center hole and fissures with different crack dip angles, coupling with or without seepage water pressure, respectively. Based on the experimental results and the $\mathrm{AE}$ characteristics during the loading process, emphasis on the crack types and crack coalescence process with different fissure angles under seepage pressure was made. The ultimate goal is to reveal the relationship between crack coalescence process and the deformation failure behavior of sandstone containing a hole and fissure under uniaxial compression.

\section{Experimental Studies}

2.1. Sandstone Material and Specimen Preparation. The experiment selected yellow sandstone as a test material, which was fine machined in the laboratory into a preliminary rock sample. When cutting, the sandstone specimens were machined along the same direction in order to avoid the effect of anisotropy on the experimental results of sandstone. The specimen dimensions were $200 \mathrm{~mm} \times 150 \mathrm{~mm} \times 80 \mathrm{~mm}$ (height $\times$ length $\times$ width). Fissure geometry is defined by two geometrical parameters: fissure angle $\alpha$, fissure length a, and diameter of hole $d$, as shown in Figure 1(a). Then, the loading surface of the sample was ground smooth, free of obvious defects and as technically required. Next, the waterjet technology was adopted to cut a $25 \mathrm{~mm}$-long single crack at the center of the specimen, leaving a hole of $10 \mathrm{~mm}$ in diameter $(d)$. Based on the fissure angle, a total of 24 specimens were made. The fissure angles of $0^{\circ}, 15^{\circ}, 30^{\circ}, 45^{\circ}$, $60^{\circ}$, and $75^{\circ}$ each corresponds to four of the specimens. The specimens of the same fissure angle were divided into Group A (without seepage pressure) and Group B (with seepage pressure). Figure 1(b) shows the specimen with a fissure angle of $\alpha=45^{\circ}$, and Table 1 lists the basic mechanical parameters.

2.2. Testing Equipment. There were three test apparatuses, namely, a loading device (DCS-200 electrohydraulic servotesting machine), an AE monitoring system (PCI-2 AE system), and a seepage pressure loading device. The DCS200 tester has both displacement and loading force control functions. The latter function was adopted for this system. In light of the tester's precision, the loading rate was set to 200 N/s. For the PCI-2 AE system, the sound intensity threshold, main amplifier intensity, and sampling frequency were set to $4 \mathrm{~dB}, 40 \mathrm{~dB}$, and $1 \mathrm{MHz}$, respectively. Four Nano30 sensors (resonance frequency: $20 \mathrm{k} \sim 400 \mathrm{kHz}$ ) were employed to collect AE signals. The seepage pressure system consists of a sealing system and a loading system. The structure of the seepage pressure system was sealed up with epoxy resin E-44 (6010) and 650 polyamide resin mixed at a ratio of $1: 1$. The cementing process is as follows: (1) connect the injection joint and the specimen with the said sealant; (2) check whether the joint was sealed up when the sealant reached the maximum strength and then use an 


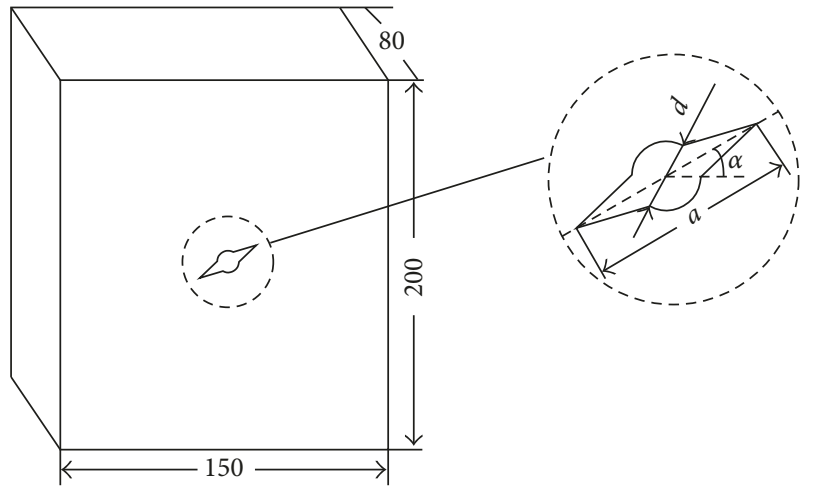

(a)

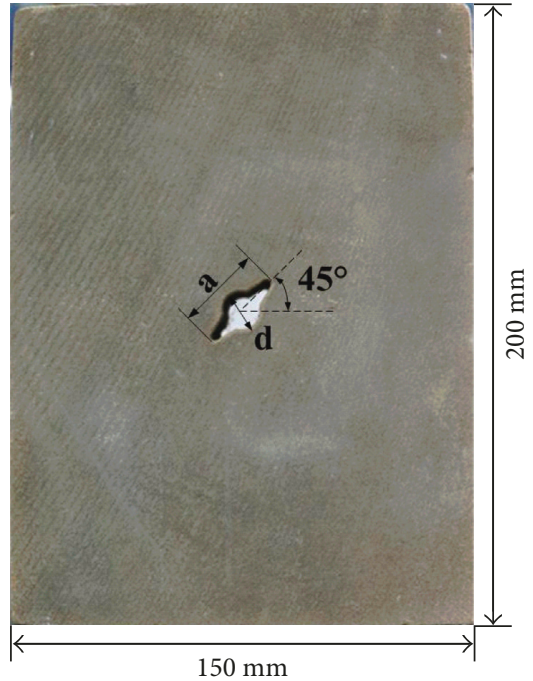

(b)

FIGURE 1: Geometry of hole and fissure in the sandstone specimens. $\alpha$ is the fissure angle, $a$ is the fissure length, and $d$ is the hole diameter. In this study, the center hole and fissure in sandstone specimens were machined by high-pressure water-jet cutting.

TABLE 1: Basic mechanical properties of sandstone specimens.

\begin{tabular}{lcccccc}
\hline $\begin{array}{l}\text { Density } \\
\left(\mathrm{g} / \mathrm{cm}^{3}\right)\end{array}$ & $\begin{array}{c}\text { Elastic modulus } \\
(\mathrm{GPa})\end{array}$ & $\begin{array}{c}\text { Compressive strength } \\
(\mathrm{MPa})\end{array}$ & $\begin{array}{c}\text { Tensile strength } \\
(\mathrm{MPa})\end{array}$ & $\begin{array}{c}\text { Poisson's } \\
\text { ratio }\end{array}$ & $\begin{array}{c}\text { Cohesion } \\
(\mathrm{MPa})\end{array}$ & $\begin{array}{c}\text { Friction angle } \\
\left({ }^{\circ}\right)\end{array}$ \\
\hline 2.37 & 16.57 & 47.87 & 2.63 & 0.21 & 10.25 & 47.87 \\
\hline
\end{tabular}

injector to displace the air in the cavity with water, aiming to improve the effect of seepage pressure loading; and (3) link up the prefabricated connectors and L-shaped elbows with the rock pieces; wrap the joints with waterproof tapes to prevent leakage during the loading.

2.3. Testing Procedure. The seepage pressure loading device was a ST hydraulic pressure pump. The pump was selfdesigned to maintain a stable water pressure during the loading. The following steps must be completed before putting the pump into use: (1) connect the delivery hose to the specimen and seal up the connection; (2) empty the water in the hose with air and then turn off the switch; (3) fill up the tank with clean water and pressurize the specimen at the beginning of the test; (4) stop pressurizing when the pressure gauge reads the required pressure; and (5) the pressurization is successful if the pressure does not drop; otherwise, check the sealing property of the pipeline. After that, the specimen should be linked up with the AE monitoring system, the strain box, and the ST seepage pressure loading device one by one. The final test equipment is illustrated in Figure 2. The water pressure in this experiment was 1.0 MPa. The whole loading process was recorded by a high-speed camera.

\section{Experimental Results and Discussion}

3.1. Effect of Fissure Angle on Mechanical Parameters of Sandstone with Seepage Pressure. Figure 3 depicts how the fissure angle $\alpha$ affected the peak strength and peak strain with or without seepage pressure. Overall, the peak strength and peak strain were significantly affected by seepage pressure.

As can be seen from Figure 3(a), the peak strength of Group B specimens was lower than that of Group A specimens. The gap of peak strength between each Group B specimen and its corresponding specimen in Group A are $22.00 \%, 20.83 \%, 19.87 \%, 19.04 \%, 9.24 \%$, and $10.13 \%$, respectively. This means that the seepage pressure greatly weakened the peak strength of the specimens; however, the weakening effect exhibited a decreasing trend with the widening of the fissure angle $\alpha$. In other words, the weakening effect is negatively correlated with the angle. Figure 3(a) also shows that the relationship between the peak strength and fissure angle remained basically the same with or without seepage pressure: the peak strength reached the minimum at the angle of $45^{\circ}$ and the maximum at the angle of $75^{\circ}$. Overall, the peak strength decreased as the fissure angle increased from $0^{\circ}$ to $45^{\circ}$ and increased as the latter grew from $45^{\circ}$ to $75^{\circ}$.

From Figure 3(b), it can be seen that the peak strain of Group B was greater than that of Group A at the same fissure angle. The gap of peak strain between each Group B specimen and its corresponding specimen in Group A are $17.14 \%, 20.29 \%, 14.07 \%, 14.15 \%, 20.80 \%$, and $24.93 \%$, respectively. The results indicate that the seepage pressure exerted a great influence on the strain, but the degree of influence depended on the fissure angle. The highest degree 


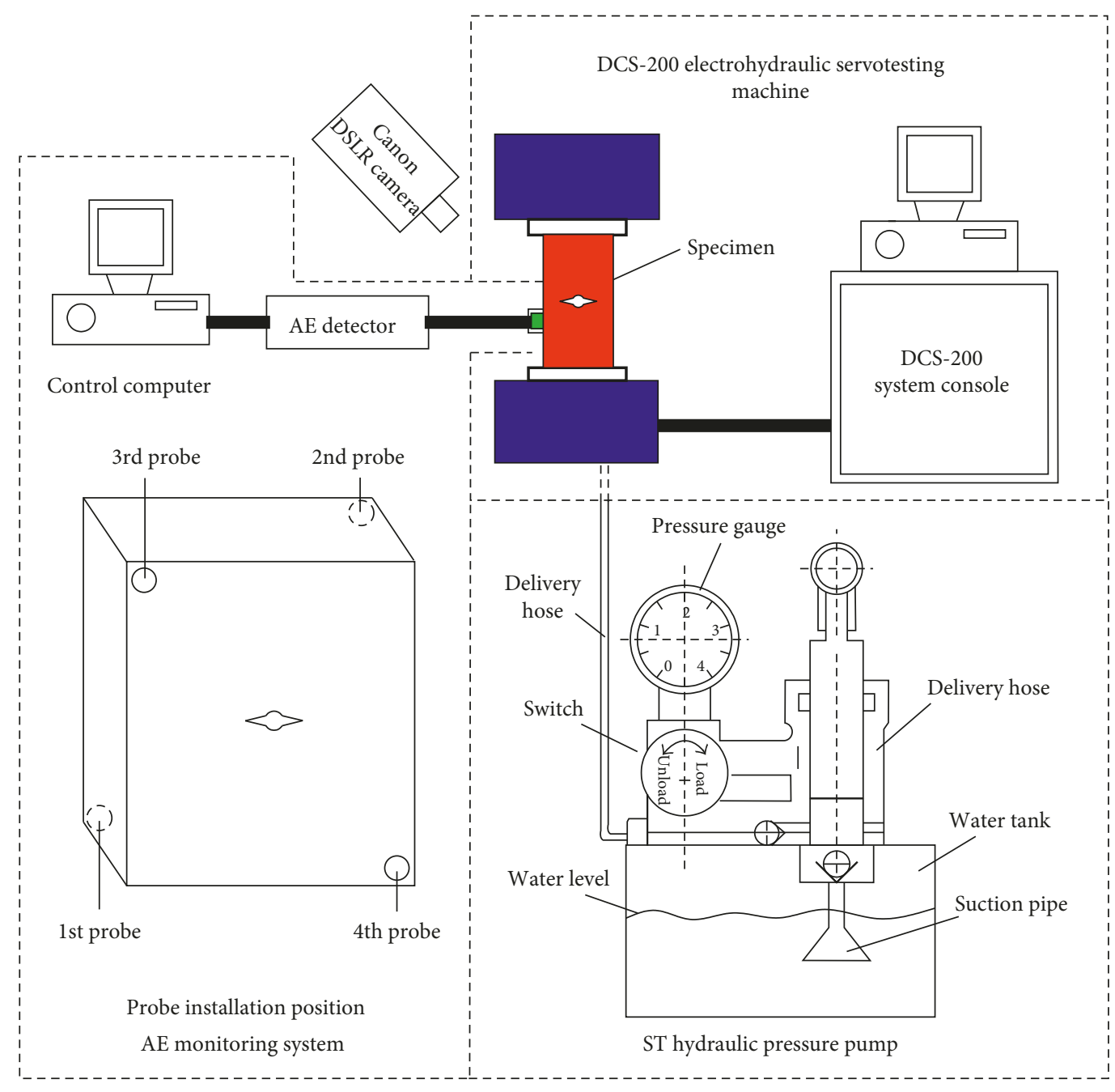

FIgURE 2: Schematic representation of experimental setup.

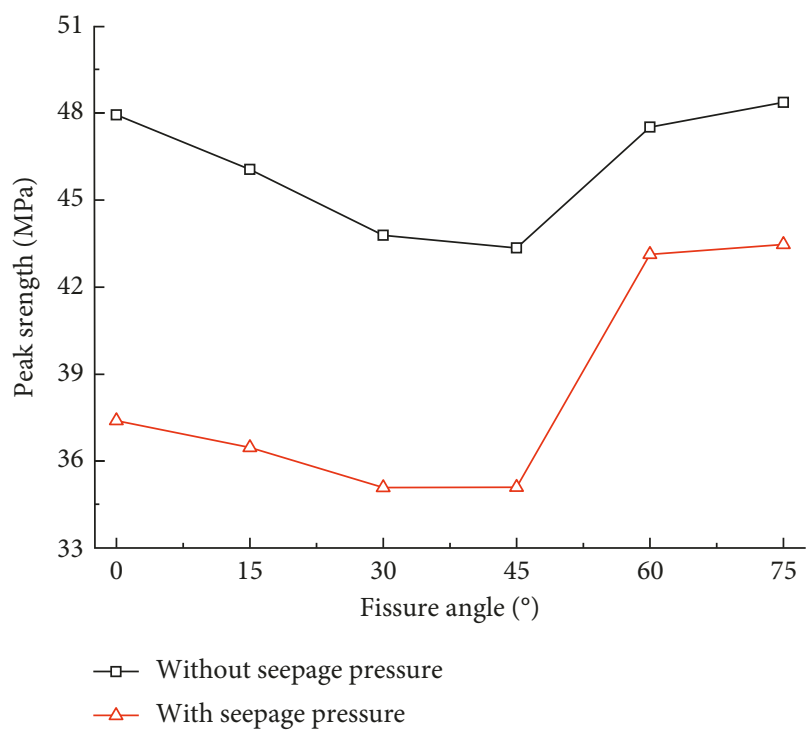

(a)

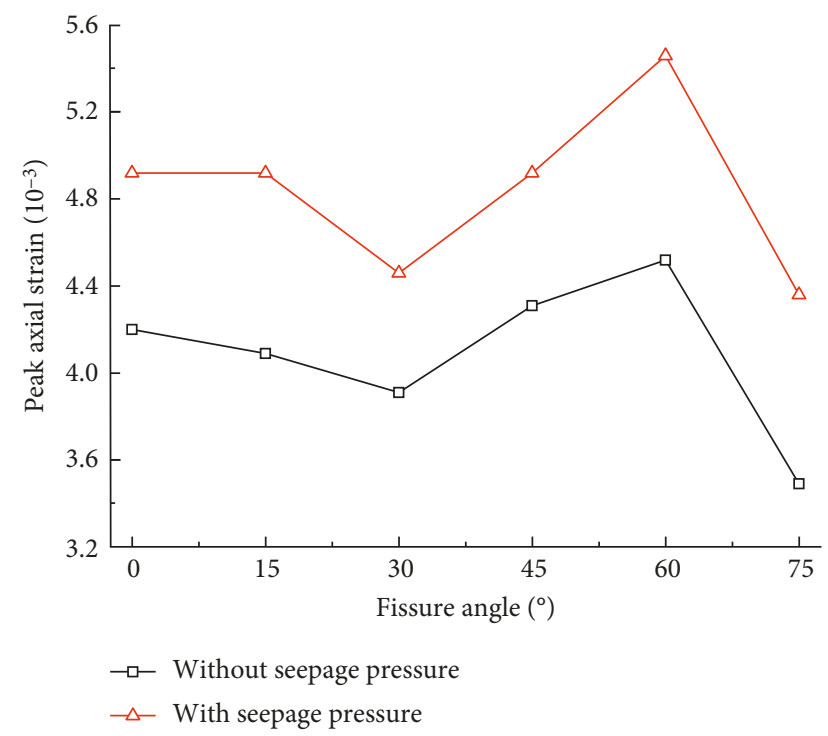

(b)

Figure 3: Effect of the fissure angle on the strength and deformation parameters for the sandstone specimens containing flaws.

(a) Relationship between peak strength and fissure angle. (b) Relationship between peak axial strain and fissure angle. 


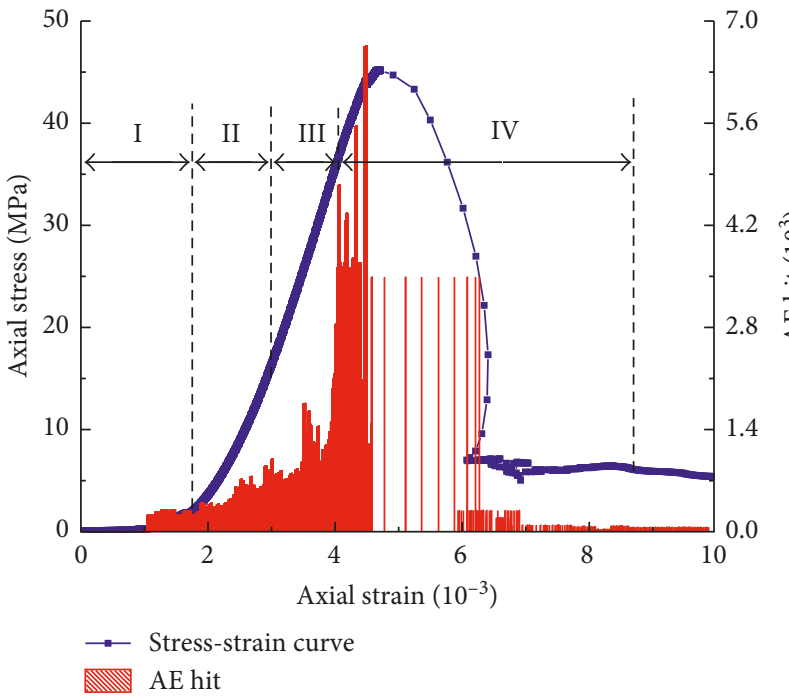

(a)

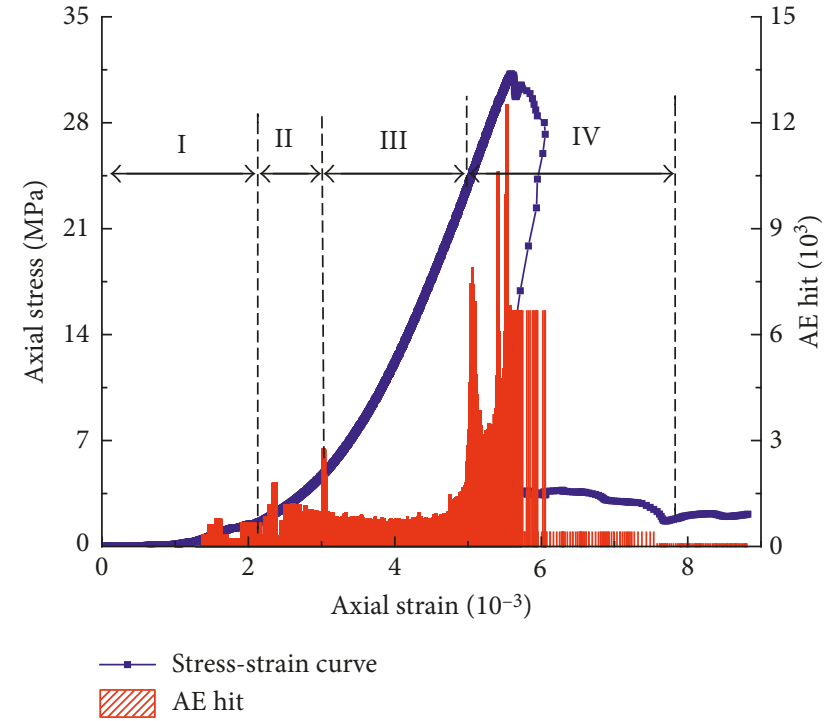

(b)

Figure 4: Relationship between axial stress-strain and AE counts of sandstone specimen containing fissure angle $\alpha=0^{\circ}$ during the whole deformation. (a) Without seepage pressure. (b) With seepage pressure.

appeared at $75^{\circ}$ and the lowest at $30^{\circ}$. Furthermore, the relationship between the peak strain and fissure angle remained basically the same with or without seepage pressure: the peak strains first decreased and then increased with the increase in fissure angle; when $\alpha \in\left[60^{\circ}, 75^{\circ}\right]$, both peak strains declined. It may be related to the brittle failure of specimens with large fissure angles during the loading.

3.2. AE Behaviors of Precraked Sandstone Specimens with Seepage Pressure. AE monitoring is useful for exploring the failure process and crack coalescence mechanism of brittle rocks, especially for flawed rocks with preexisting fissures. Scholars analyzed the AE counts and AE energy of rock during the deforming and fracturing process $[3,20]$. Hence, these parameters were combined with the stress-strain curve to analyze the features of precracked specimen during seepage pressure-induced process and to identify the precursor features of rock damages.

No matter how large the fissure angle, most rock specimens shared similar features of deformation. The rock failure process always consists of four stages: microcrack closure, elastic deformation, crack growth and propagation, and final failure. Due to space limitations, only the specimens with the fissure angle of $0^{\circ}$ were detailed here. The stress-strain curve and AE test results are shown in Figure 4.

(1) Microcrack closure stage: in this stage, the uniaxial compression stress-strain curve of the precraked sandstone specimen was downward concave. Both specimens A0 and B0 experienced the fissure closure or microcracks initiation at this stage. The AE stress level of A0 was $2.91 \mathrm{MPa}, 6.44 \%$ of the peak strength. The stress of $\mathrm{B} 0$ was $2.16 \mathrm{MPa}, 6.92 \%$ of the peak strength. In this phase, the two specimens had very limited AE counts.

(2) Elastic deformation stage: the stress levels of $\mathrm{A} 0$ and B0 were $2.91 \sim 15.53 \mathrm{MPa}$ and $2.16 \sim 4.71 \mathrm{MPa}$, respectively. The microcracks continued to initiate and propagate. The stress-strain curve of A0 was steeper than that of $\mathrm{B} 0$, indicating that it had a greater elastic modulus. This is because the strength of B0 was weakened by the seepage pressure. When the stress reaches some extent, cracks begin to initiate. Some $\mathrm{AE}$ counts can be seen in this phase. But the $\mathrm{AE}$ behaviors of specimen with seepage pressure are different from that of specimen without seepage pressure, which is related to seepage pressure. The $\mathrm{AE}$ counts of $\mathrm{A} 0$ increased steadily, while two large $\mathrm{AE}$ counts were observed on $\mathrm{B} 0$ due to the emergence of tensile cracks at the fissure tip under seepage pressure.

(3) Crack growth and propagation stage: the stress levels of A0 and B0 were 15.53 36.64 MPa and 4.71 24.62 MPa, respectively. This stage was dominated by the growth and propagation of cracks. When the stress increased to the initiation stress, the macrotensile cracks started to appear from the fissure tip. At this time, both $\mathrm{A} 0$ and $\mathrm{B} 0$ reached their peak AE counts: 10,167 versus 3,672 . With the acceleration of crack propagation, the $\mathrm{AE}$ counts of A0 surged up and those of B0 kept a steady growth.

(4) Failure stage: as the loading continued, the crack propagation gradually becomes unstable, and many secondary cracks coalescence to each other. When the load increased to a certain value, the $\mathrm{AE}$ counts of the two specimens rocketed up to the maximum 


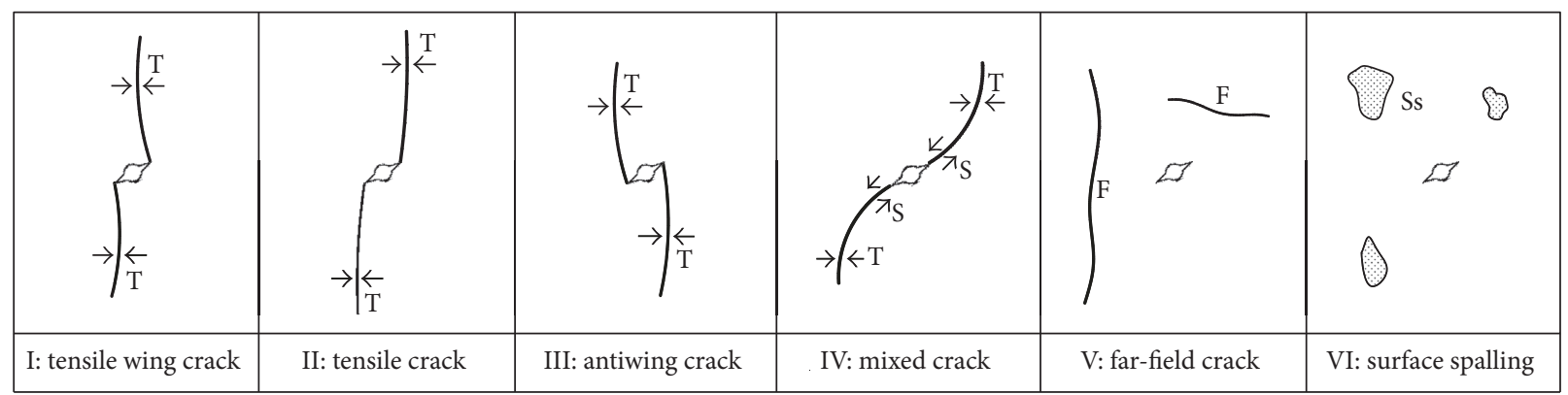

FIGURE 5: Different crack types in the specimen. T: tensile crack; S: shear crack; F: far-field crack; Ss: surface spalling.

values (14,253 versus 5,835). The corresponding stress levels of the two specimens were $93.52 \%$ and $97.50 \%$ of peak strength, respectively. As stress quickly fell down to the residual strength, the $\mathrm{AE}$ counts plunged drastically. In the meantime, the specimens appear surface spalling and final failure, owing to the coalescence of secondary cracks. In the postbrittle failure phase, the residual strength of A0 (6.2 $\mathrm{MPa})$ was higher than that of B0 (2.3 MPa). A possible explanation for the lower residual strength of B0 goes as follows: under the seepage pressure, the stress intensity factor $K_{I}$ [21] on the crack tip went up, which intensified the propagation and failure of secondary cracks.

\section{Failure Characteristics}

4.1. Crack Coalescence Type. According to the classification of cracks in previous experimental results $[3,22]$, the cracks in this test mainly include tensile wing crack (I), tensile crack (II), antiwing crack (III), mixed crack (IV), far-field crack (V), and surface spalling (VI), as shown in Figure 5.

Tensile wing crack I usually initiates along the vertical direction to preexisting fissure, and then gradually departs toward the direction of axial stress, and finally develops along the direction of axial stress. By contrast, tensile crack II initiates from upper or under tip of fissure and propagates along the direction of axial stress. Crack type III is reverse to that of crack type II, which is referred to as "antiwing crack." The antiwing crack also initiates from upper or under tip of fissure and propagates along the direction of axial stress. Due to space limitations, only some of the specimens were selected for failure feature analysis.

4.2. Crack Coalescence Process. As shown in Figure 6(a), A0 mainly had type I (initial cracks), type II, type V, and type VI cracks. The crack propagation process is detailed as follows: first, type I cracks initiated at the crack tip of the hole; with the increase stress, the type I cracks at the right end stopped propagating, while those at the left end continued to propagate in a near arc shape along the direction of axial stress. At the same time, the type II cracks generated at the right tip developed into two tensile cracks, one of which propagated along the right surface of the specimen and the other along the boundary until the specimen was damaged. Before the ultimate failure, the specimen suffered from a few type VI and type V cracks at its upper right and left lower ends. The failure specimen was relatively complete and lightly fragmented.

Figure 6(b) depicts the final failure of B0. The specimens are mainly type I (initial cracks), type IV, type V, and type VI cracks. The crack propagation process is detailed as follows: first, type I cracks initiated at the right tip and the hole; under the continuous loading and seepage pressure, the type I cracks at the right end propagated along the upper right boundary of the specimen, while those initiated at the hole stopped propagating once penetrating into type $\mathrm{V}$ far-field cracks. In the meantime, the type IV secondary cracks, emerged from the right tip of the fissure, spread toward the right end surface and coalescence near the right end surface into the type $\mathrm{V}$ far-field cracks initiated from the right boundary, leading to the macro failure of the specimen. During the loading test, water kept seeping from the fissure. The largest amount of seepage was concentrated at the cracks around the hole. The seepage was accompanied by the large surface spalling.

The crack initiation, propagation, and coalescence modes of A0 and B0 are compared below. The initial cracks were both type I tensile wing cracks. The only difference lies in the initiation location is those of A0 emerged from the crack tip, while those of B0 started from the hole. As for crack propagation, A0 was damaged by the propagation of types I and II cracks from the crack tip along the loading direction to the boundary; B0 was damaged in a similar way, except that the cracks penetrated into each other twice. In terms of the failure mode, A0 obviously underwent tensile failure, while B0 suffered from tensileshear mixed failure (mainly tensile failure, plus some local shear failures). Considering the failure results, B0 was more seriously damaged and fragmented than A0.

The obvious difference between the two specimens was induced by the following factors: the seepage pressure, coupled with the fissure, and altered the stress in the transmission process. Due to the changing stress, the hole was unevenly pressurized so that the cracks were not initiated at the tip of the fissure. Moreover, the "wedging" effect of seepage pressure weakened the cementing ability of the rock particles and softened the rock surface, causing massive surface spalling around the hole. 


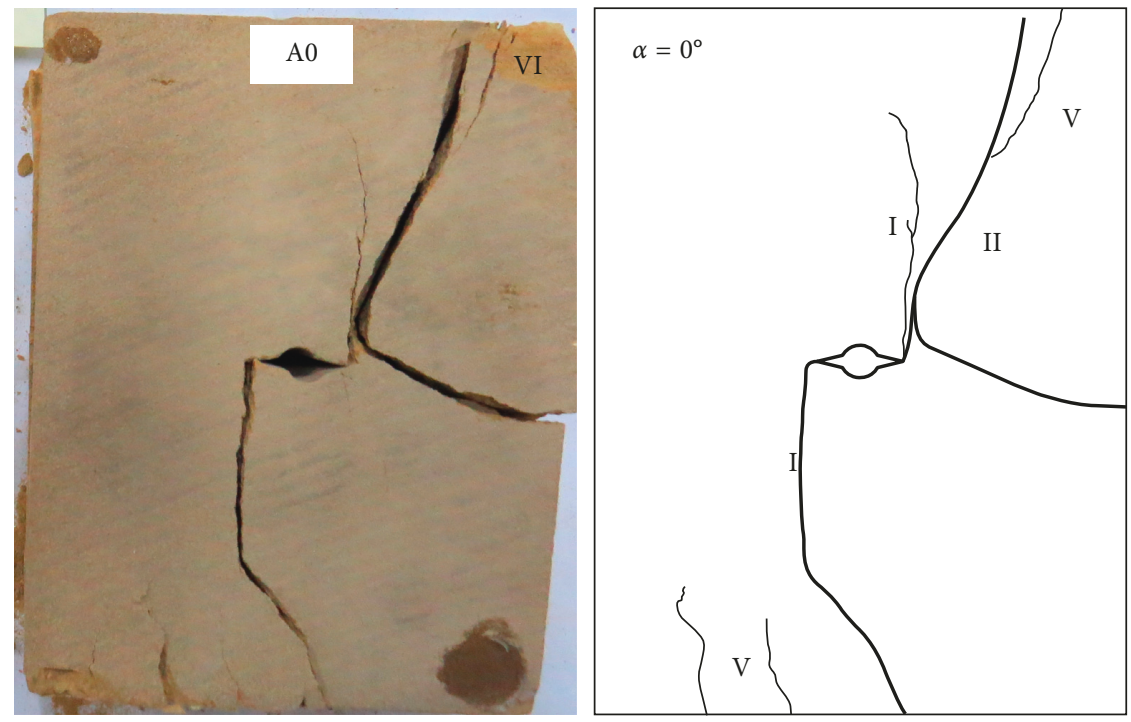

(a)
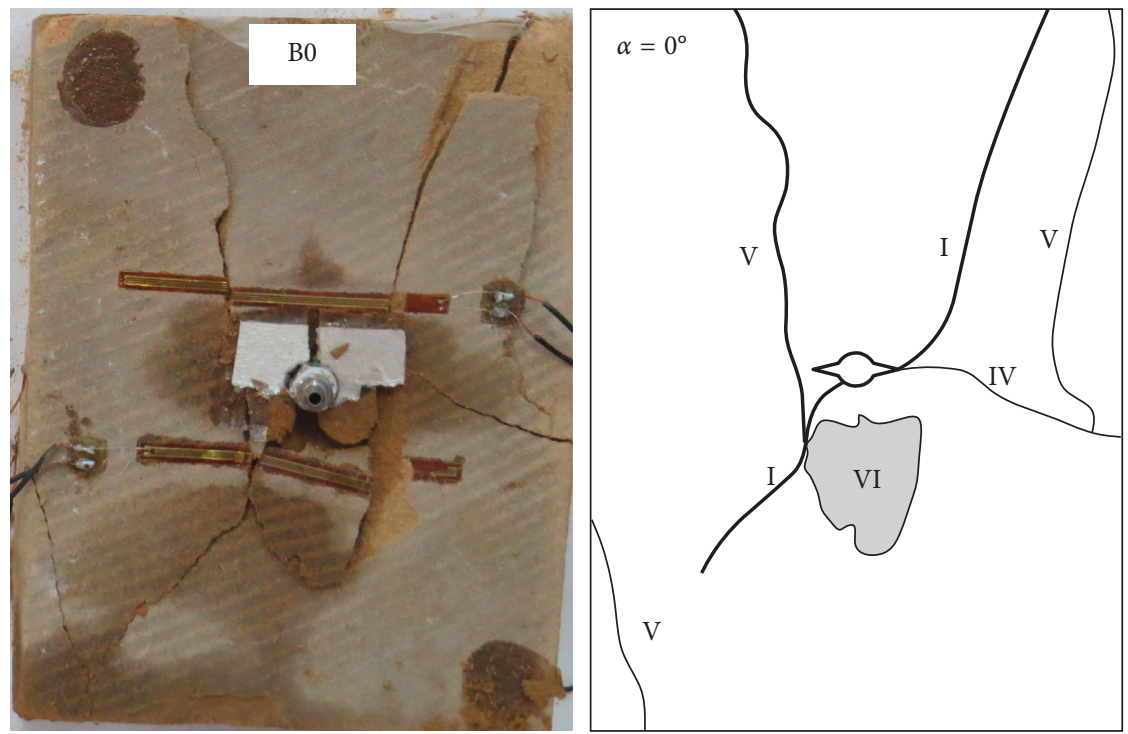

(b)

FIGURE 6: Effect of seepage pressure on ultimate failure modes of sandstone specimens containing fissure angle $\alpha=0^{\circ}$. (a) Without seepage pressure. (b) With seepage pressure.

According to Figure 7(a), specimen A30 mainly had type I, type III (initial cracks), type V, and type VI cracks; the failure mode was a typical tensile failure caused by the propagation of antiwing cracks to the specimen boundary. Except far-field cracks, the other cracks were all initiated at the crack tip. The figure also reveals that several secondary cracks initiated after the main crack. Under multiple tensile stresses, two symmetrical fragile zones were formed around the fissure. Meanwhile, surface spalling was observed at the upper end and the right boundary of the specimen. It can be seen from Figure 7(b) that the specimen mainly suffered from shear failure. The surface has an obvious slip and lots of friction powders.

It can be seen from Figure 8 that specimen A30 had mainly type III (initial cracks), type V, and type VI cracks; the failure mode was tensile failure caused by the propagation of the cracks from the two ends of the hole to the end of the specimen. The propagation process is detailed as follows: two antiwing cracks emerged at the two ends of the fissure and propagated along the direction of axial stress; with the increase of stress, the propagation shifted from stable expansion to unstable expansion. After the type III initial cracks coalescence with two type V far-field cracks, the type III antiwing cracks continued to propagate along the upper and lower boundaries of the specimen until the ultimate deformation failure. Large surface spalling was observed in the left of the specimen from Figure 8(a). The author held that the stress was likely to concentrate in the crack coalescence area, surface spalling will appears in the specimen with continued loading. It can be seen from 

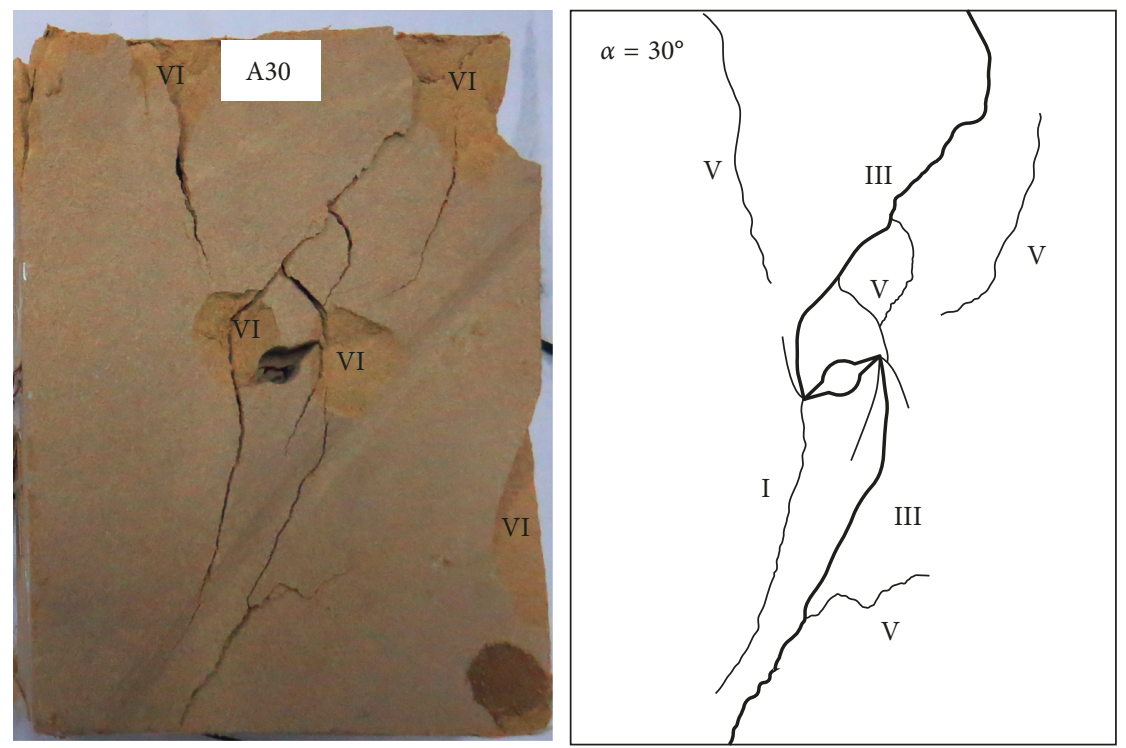

(a)

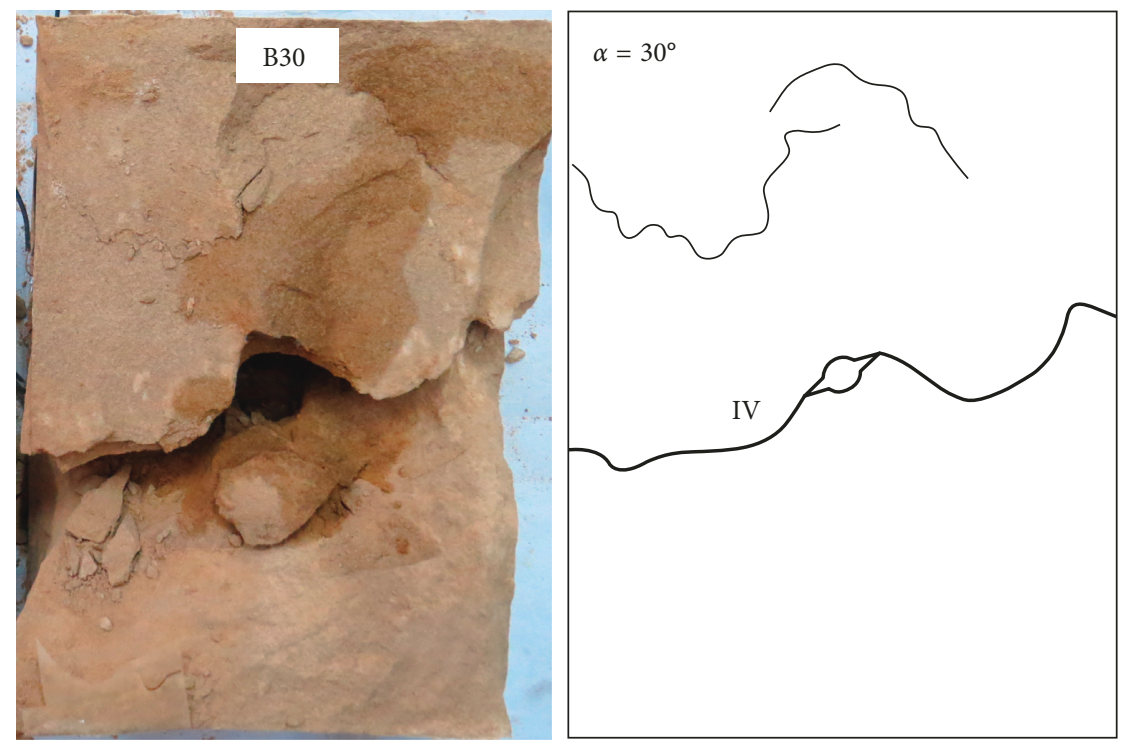

(b)

FIGURE 7: Effect of seepage pressure on ultimate failure modes of sandstone specimens containing fissure angle $\alpha=30^{\circ}$. (a) Without seepage pressure. (b) With seepage pressure.

Figure 8(b) that specimen B75 mainly had type $\mathrm{V}$ and type VI cracks; the failure mode was the tensile-shear mixed failure. On the surface, the secondary cracks propagated and coalescence into far-field cracks. The fragments of varied sizes appeared on the left of the cracks and at the upper right end of the specimen. More surface spalling from B75 than A75 was observed, indicating that the specimen was more likely to failure under seepage pressure.

According to the types of cracks on 24 specimens under uniaxial compression, far-field cracks were observed in all the flawed specimens. It makes an agreement with the conclusions obtained by many laboratory tests $[3,22]$. Hence, the initiation of far-field cracks has nothing to do with the size of the fissure angle. For the specimens under seepage pressure, the rocks were mostly fragmented into powders. The phenomenon testifies the sandstone degradation effect of water, which dissolved the various minerals in the sandstone. Furthermore, the seepage pressure weakened the positive stress on the fissures, lowered the type I stress intensity factor at the tip of the fissures, and added to the chance of tensile-shear mixed failure. No matter if the seepage pressure was applied, some surface spalling was observed at the fissure angle of $30^{\circ}$ or $75^{\circ}$. In this case, the cracks propagated in a much more complex way, and the damages were greater than the specimen with the angle of $0^{\circ}$. Compared with horizontal cracks, the specimens with tilted cracks were more likely to form local fragile zones, which are favourable for the deformation failure of rocks. 

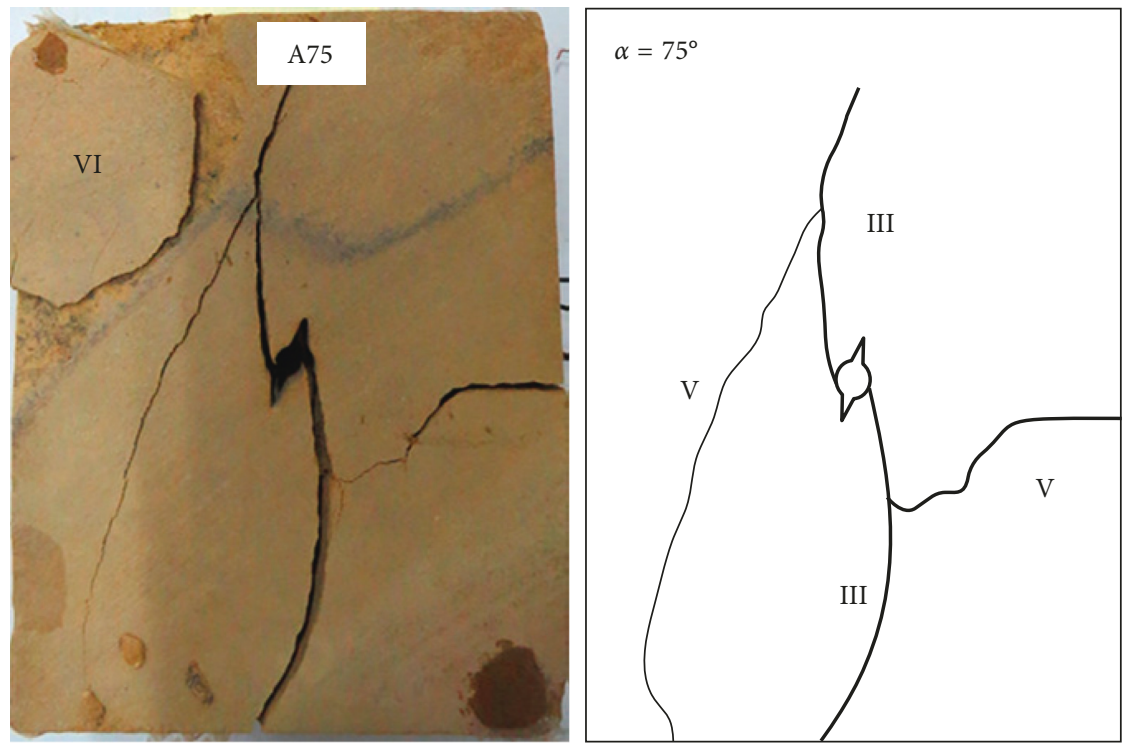

(a)
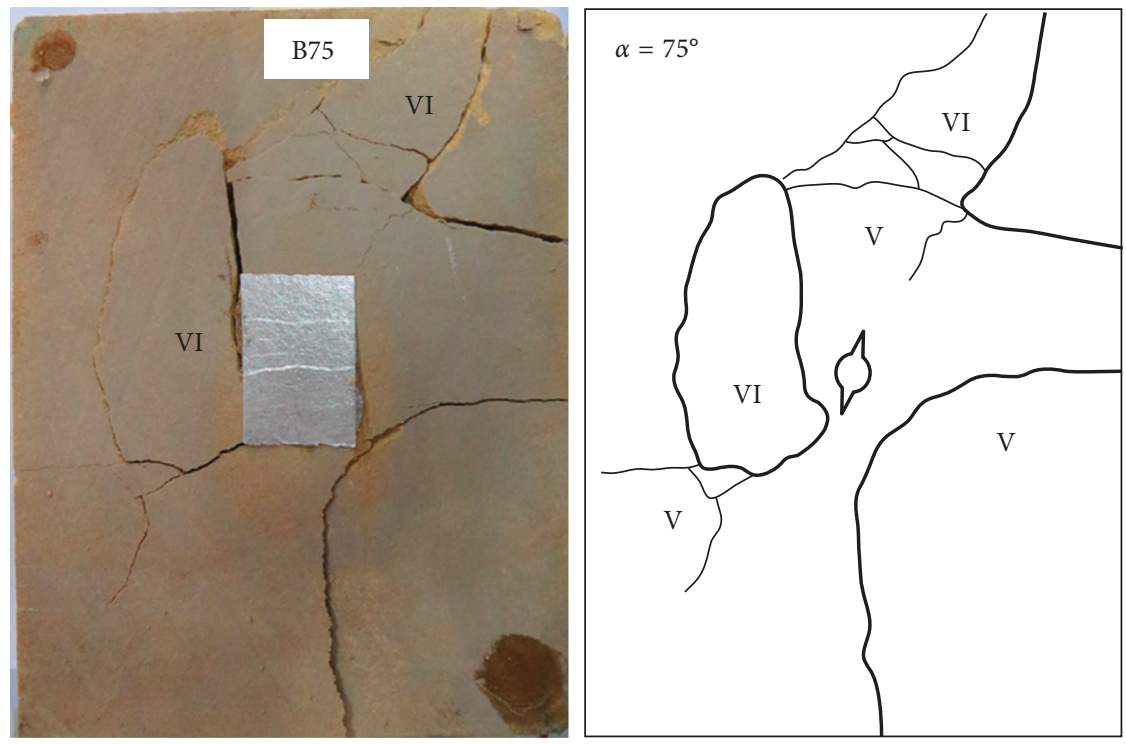

(b)

FIGURE 8: Effect of seepage pressure on ultimate failure modes of sandstone specimens containing fissure angle $\alpha=75^{\circ}$. (a) Without seepage pressure. (b) With seepage pressure.

Under seepage pressure, the typical failure features of the specimens varied with the fissure angles: the specimens with small fissure angles, that is, $\left[0^{\circ}, 30^{\circ}\right]$, mainly underwent the initiation of type I cracks and tensile failure; those with medium fissure angles, that is, $\left[30^{\circ}, 60^{\circ}\right]$, suffered from the initiation of type III cracks and shear failure; those with large fissure angles, that is, $\left[60^{\circ}, 75^{\circ}\right]$, were subject to the initiation of type VI cracks and prone to tensile-shear mixed failure.

\section{Conclusions}

(1) Combined with axial stress-strain curves, photographic monitoring results and the output of $\mathrm{AE}$ counts and rock failure process can be generally divided into four stages: microcrack closure, elastic deformation, crack growth and propagation, and final failure. The $\mathrm{AE}$ event parameters were good indicators of the rock deformation and fracturing features and important identifiers of failure precursors. During the loading process, each sudden increase (decrease) in each AE count was accompanied by the initiation (propagation or coalescence) of microcracks. In addition, the AE counts of the specimens with seepage pressure were significantly lower than those of the samples without seepage pressure.

(2) The weakening effect of seepage pressure on the specimen peak strength was negatively correlated 
with the fissure angle $\alpha$, that is, the larger the fissure angle, the poorer the weakening effect of seepage pressure. The seepage pressure also exerted a great influence on the strain, but the degree of influence depended on the fissure angle.

(3) The high-speed camera technology was applied to examine failure process of precracked specimens under seepage pressure. The results show that the tensile failure was the main failure mode of specimens without seepage pressure, while the failure modes of specimens with seepage pressure were more complicated. Under seepage pressure, the specimens with small fissure angles, that is, $\left[0^{\circ}, 30^{\circ}\right]$, mainly underwent tensile failure, plus some local shear failures; those with medium fissure angles, that is, $\left[30^{\circ}, 60^{\circ}\right]$, suffered from shear failure; those with large fissure angles, that is, $\left[60^{\circ}, 75^{\circ}\right]$, were prone to tensile-shear failure.

\section{Conflicts of Interest}

The authors declare that they have no conflicts of interest.

\section{Acknowledgments}

This research received funding from the projects $(51174228$ and 11772358) supported by National Natural Science Foundation of China.

\section{References}

[1] C. H. Park and A. Bobet, "Crack coalescence in specimens with open and closed flaws: a comparison," International Journal of Rock Mechanics \& Mining Sciences, vol. 46, no. 5, pp. 819-829, 2009.

[2] A. V. Dyskin, E. Sahouryeh, R. J. Jewell, H. Joer, and K. B. Ustinov, "Influence of shape and locations of initial 3-D cracks on their growth in uniaxial compression," Engineering Fracture Mechanics, vol. 70, no. 15, pp. 2115-2136, 2003.

[3] S. Q. Yang and H. W. Jing, "Strength failure and crack coalescence behavior of brittle sandstone samples containing a single fissure under uniaxial compression," International Journal of Fracture, vol. 168, no. 2, pp. 227-250, 2011.

[4] H. Lin, W. Xiong, and Q. X. Yan, "Three-dimensional effect of tensile strength in the standard Brazilian test considering contact length," Geotechnical Testing Journal, vol. 39, no. 1, pp. 137-143, 2016.

[5] B. Shen, "The mechanism of fracture coalescence in compression-experimental study and numerical simulation," Engineering Fracture Mechanics, vol. 51, no. 1, pp. 73-85, 1995.

[6] L. N. Y. Wong and H. H. Einstein, "Crack coalescence in molded gypsum and Carrara marble: part 1. Macroscopic observations and interpretation," Rock Mechanics \& Rock Engineering, vol. 42, no. 3, pp. 475-511, 2009.

[7] L. N. Y. Wong and H. H. Einstein, "Systematic evaluation of cracking behavior in specimens containing single flaws under uniaxial compression," International Journal of Rock Mechanics \& Mining Sciences, vol. 46, no. 2, pp. 239-249, 2009.

[8] A. Bobet and H. H. Einstein, "Fracture coalescence in rocktype materials under uniaxial and biaxial compression," International Journal of Rock Mechanics \& Mining Sciences, vol. 35, no. 7, pp. 863-888, 1998.
[9] S. Q. Yang, D. S. Yang, H. W. Jing, Y. H. Li, and S. Y. Wang, "An experimental study of the fracture coalescence behaviour of brittle sandstone specimens containing three fissures," Rock Mechanics \& Rock Engineering, vol. 45, no. 4, pp. 563-582, 2012.

[10] X. P. Zhou, H. Cheng, and Y. F. Feng, "An experimental study of crack coalescence behaviour in rock-like materials containing multiple flaws under uniaxial compression," Rock Mechanics \& Rock Engineering, vol. 47, no. 6, pp. 1961-1986, 2014.

[11] R. H. Cao, P. Cao, H. Lin, C.-z. Pu, and K. Ou, "Mechanical behavior of brittle rock-like specimens with pre-existing fissures under uniaxial loading: experimental studies and particle mechanics approach," Rock Mechanics \& Rock Engineering, vol. 49, no. 3, pp. 763-783, 2016.

[12] R. H. Cao, P. Cao, X. Fan, X. Xiong, and H. Lin, “An experimental and numerical study on mechanical behavior of ubiquitous-joint brittle rock-like specimens under uniaxial compression," Rock Mechanics \& Rock Engineering, vol. 49, no. 11, pp. 1-20, 2016.

[13] H. Wang, H. Lin, and P. Cao, "Correlation of UCS rating with Schmidt hammer surface hardness for rock mass classification," Rock Mechanics and Rock Engineering, vol. 50, no. 1, pp. 195-203, 2017.

[14] M. Bahaaddini, G. Sharrock, and B. K. Hebblewhite, "Numerical investigation of the effect of joint geometrical parameters on the mechanical properties of a non-persistent jointed rock mass under uniaxial compression," Computers \& Geotechnics, vol. 49, no. 20, pp. 206-225, 2013.

[15] R. H. C. Wong, P. Lin, and C. A. Tang, "Experimental and numerical study on splitting failure of brittle solids containing single pore under uniaxial compression," Mechanics of Materials, vol. 38, no. 1-2, pp. 142-159, 2006.

[16] X. P. Zhang and L. N. Y. Wong, "Cracking processes in rocklike material containing a single flaw under uniaxial compression: a numerical study based on parallel bonded-particle model approach," Rock Mechanics \& Rock Engineering, vol. 45, no. 5, pp. 711-737, 2012.

[17] Y. L. Zhao, P. Cao, H. Lin et al., "Rheologic fracture mechanism and failure criterion of rock cracks under compressiveshear load with seepage water pressure," Chinese Journal of Geotechnical Engineering, vol. 30, no. 4, pp. 511-517, 2008.

[18] Z. H. Zhou, P. Cao, and Z. Y. Ye, "Crack propagation mechanism of compression-shear rock under static-dynamic loading and seepage water pressure," Journal of Central South University, vol. 21, no. 4, pp. 1565-1570, 2014.

[19] L. Li, Q. Meng, S. Wang, G. Li, and C. Tang, "A numerical investigation of the hydraulic fracturing behaviour of conglomerate in Glutenite formation," Acta Geotechnica, vol. 8, no. 6, pp. 597-618, 2013.

[20] Q. Liu, J. Xu, X. Liu, J. Jiang, and B. Liu, "The role of flaws on crack growth in rock-like material assessed by AE technique," International Journal of Fracture, vol. 193, no. 2, pp. 1-17, 2015.

[21] J. C. Newman and I. S. Raju, "An empirical stress-intensity factor equation for the surface crack," Engineering Fracture Mechanics, vol. 15, no. 1, pp. 185-192, 1981.

[22] S. Q. Yang, Y. H. Dai, L. J. Han, and Z. Q. Jin, “Experimental study on mechanical behavior of brittle marble samples containing different flaws under uniaxial compression," Engineering Fracture Mechanics, vol. 76, no. 12, pp. 1833-1845, 2009. 


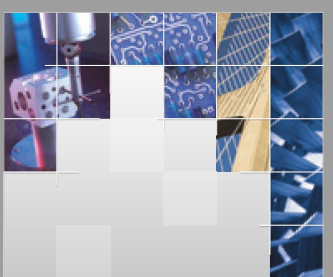

\section{Enfincering}
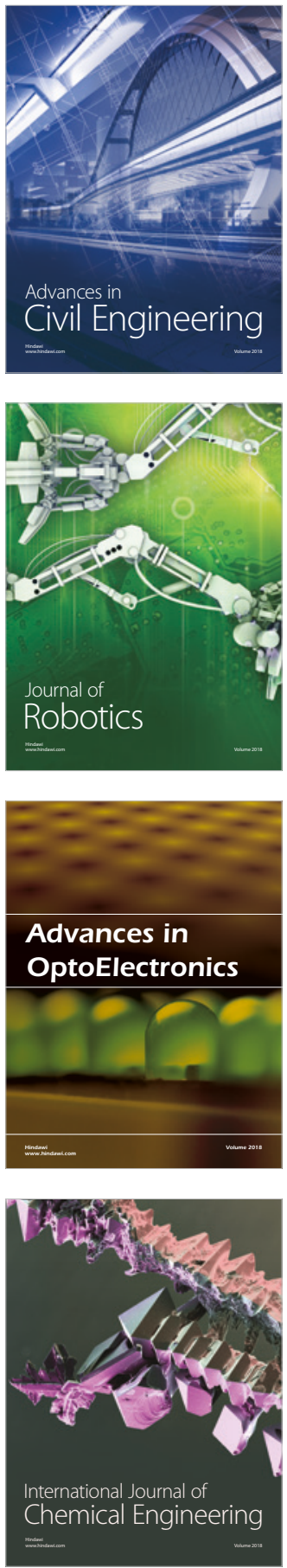

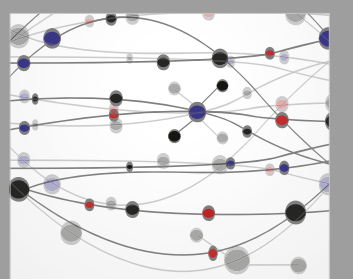

\section{Rotating \\ Machinery}

The Scientific World Journal

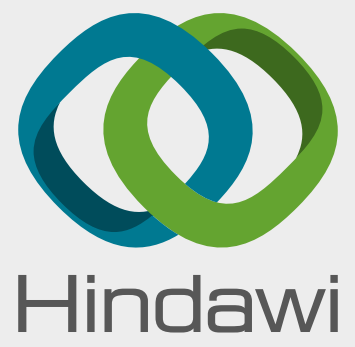

Submit your manuscripts at

www.hindawi.com
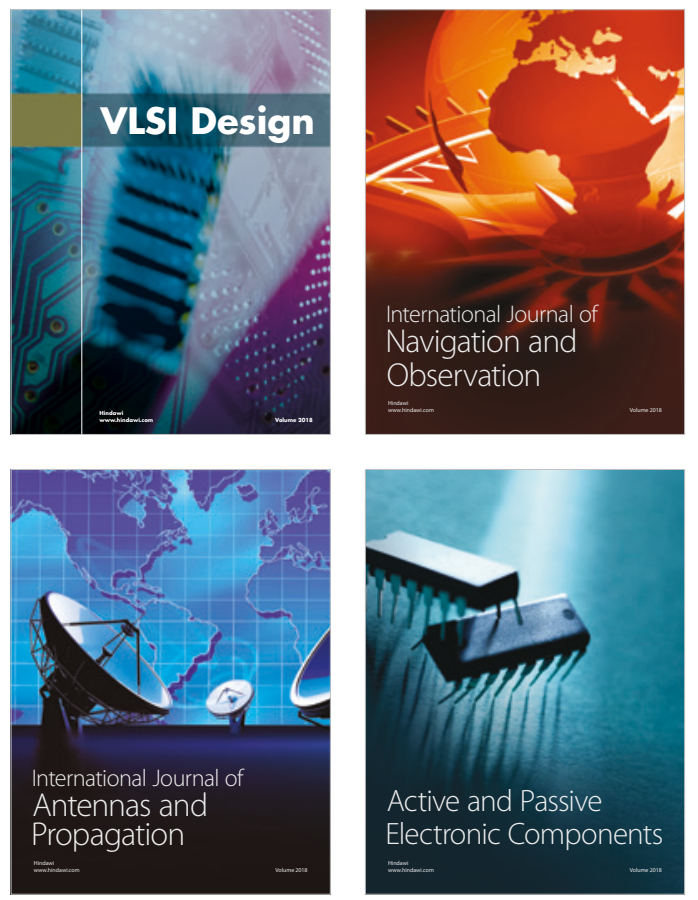
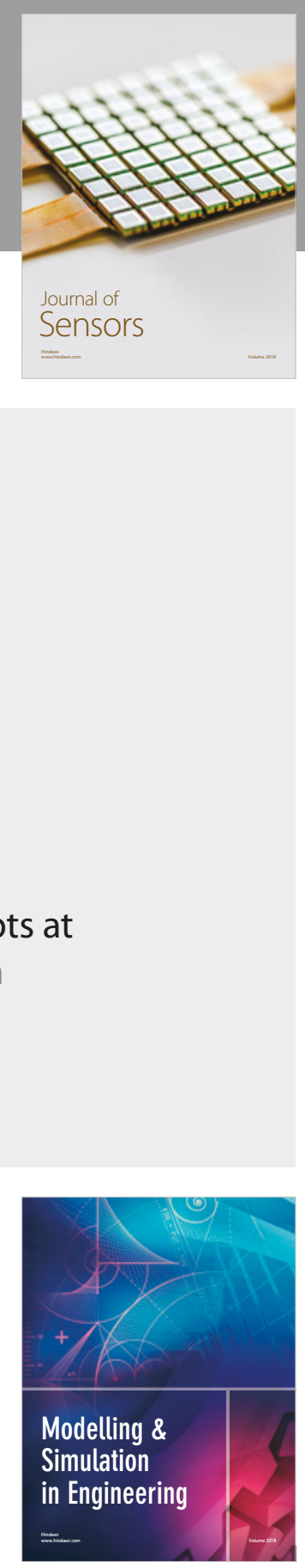

\section{Advances \\ Multimedia}
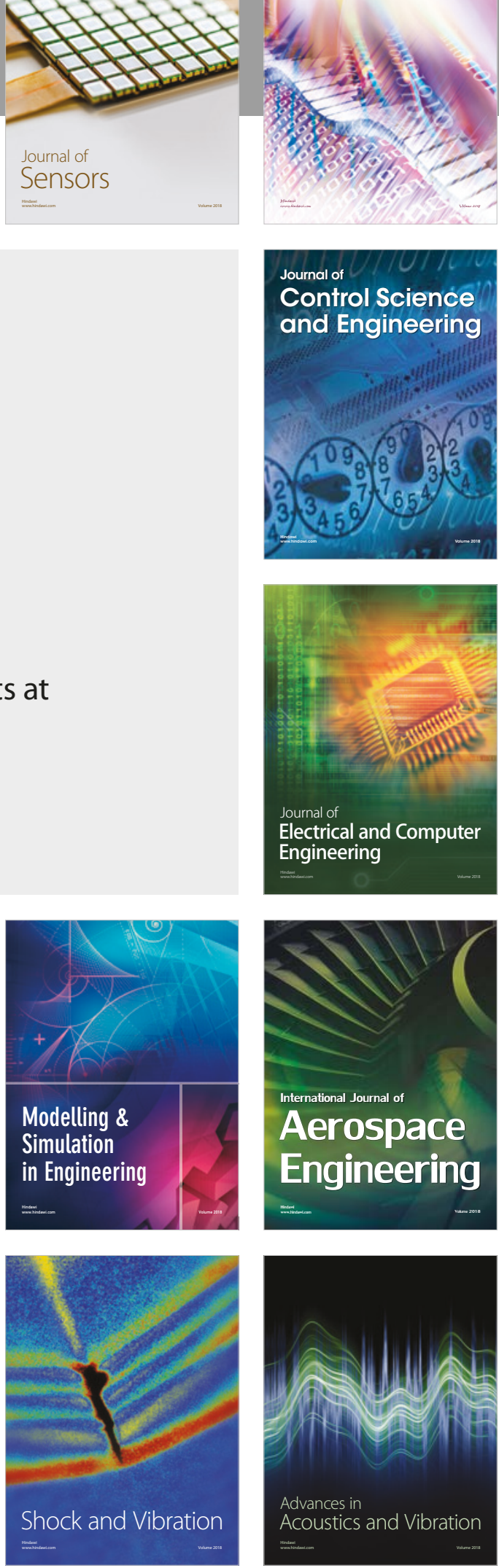